\title{
Maternal Smoking during Pregnancy and Sudden Infant Death Using the National Maternal and Infant Health Survey: A Case-Case Study
}

\author{
Kathleen Franciska Brookfield ${ }^{1}$, James Dean Wilkinson ${ }^{1}$, Barbara Luke ${ }^{2}$, Kristopher Arheart ${ }^{1}$, \\ Eleni Sfakianaki ${ }^{1}$
}

${ }^{1}$ Miller School of Medicine, University of Miami, Miami, USA; ${ }^{2}$ Michigan State University, East Lansing, USA.

Email: kbrookfield@med.miami.edu

Received January $12^{\text {th }}, 2011$; revised March $1^{\text {st }}, 2011$; accepted April $1^{\text {st }}, 2011$.

\begin{abstract}
We utilized data from the National Maternal and Infant Health Survey (NMHIS) to analyze the risk of SIDS and other infant deaths among women who smoke during pregnancy adjusting for potentially modifiable risk factors such as secondhand smoke exposure and breastfeeding. The following variables were assessed with respect to risk for SIDS and other infant deaths: smoking exposure, level of education, infant and maternal age, infant and maternal birthweight, maternal BMI, gender, secondhand smoke exposure, breast feeding, prenatal vitamins, WIC, multiple gestation, sleep apnea monitor prescription, sleep apnea incidents and maternal alcohol use. Univariate analysis and multivariate logistic regression were performed to identify variables significantly associated with the odds of mortality from SIDS. Analysis utilized weighted estimates using SUDAAN 9.0.0 to adjust for design effects. A p-value $<0.01$ was considered statistically significant. Women who smoked during pregnancy were 1.83 times more likely to give birth to an infant that died from SIDS versus some other cause of death, OR $(95 \%)=1.83(1.33,2.51)$. Other Race infants and Black infants were more likely to suffer SIDS mortality than White infants, but the result was not significant in the final model. Other modifiable risk factors, such as secondhand smoke exposure and breast feeding, were not significant predictors of SIDS mortality. Independent of sociodemographic variables and other potential risk factors for SIDS death, maternal smoking was associated with an increased risk of SIDS death versus other death. This study highlights the importance of screening all pregnant women for tobacco use and emphasizes the importance of smoking cessation to decrease the risk of infant death from SIDS.
\end{abstract}

Keywords: Sudden Infant Death, Smoking, Pregnancy, Passive Smoking, Breastfeeding

\section{Introduction}

Sudden Infant Death Syndrome (SIDS) is the leading cause of postneonatal death among all racial and ethnic groups, representing nearly one-third of such deaths. The incidence of SIDS peaks in the second or third month of life, and subsequently decreases over the first year of life. Two components of cigarette smoke potentially responsible for a role in SIDS pathophysiology are carbon monoxide (CO) and nicotine. These toxins, which cross the placental barrier, have been demonstrated to alter the physiologic development of organs and tissues most susceptible to hypoxia damage, including the brain and heart in animal models [1-4]. Altered autonomic nervous system function has been described in infants born to mothers who smoked during preg- nancy [5-7]. It has been hypothesized that $\mathrm{CO}$ exposure from maternal smoking may have an effect on postnatal electrophysiological remodeling which could predispose the infant heart to fatal arrythmias [3]. Exposure to CO in concentrations comparable to that of human smokers induced a statistically significant delay in action potential (AP) duration in a rat model [3]. The potential effect of $\mathrm{CO}$ exposure on AP duration is a plausible explanation for an arrhythmia resulting in sudden death.

In addition to $\mathrm{CO}$ exposure, nicotine exposure has also been implicated as a key cigarette component related to the cardiorespiratory events characteristic of SIDS [8]. Although not associated with restricting uterine blood flow, the cardiovascular effects of nicotine increase the fetal heart rate while decreasing fetal heart rate variability $[9,10]$. Studies demonstrating that pre- 
natal exposure to cigarette smoke alters lung mechanics in infants and children have been bolstered by animal experiments linking nicotine to altered alveolar architecture, pulmonary hypoplasia, increases in collagen deposition and decreases in elastin content [11]. Nicotine is also known to adversely affect neural networks controlling respiration by acting as a fetal neuroteratogen [2].

While many toxic, infectious, metabolic, physiologic and socioeconomic factors have been proposed as causes of SIDS, less attention has focused on the role of modifiable behaviors such as smoke exposure (from maternal and secondhand exposures) and breast-feeding $[12,13]$. Smoking during pregnancy continues to be a significant public health problem, with $13.8 \%$ of women in 2005 admitting to this behavior while pregnant [14]. Smoking rates during pregnancy in the United Kingdom were $17 \%$ in the same year and the rates in Canada were $24 \%$ [15]. The role of secondhand smoke exposure in the pathophysiology of SIDS is less clear, as is the role of lower socioeconomic status which has been reported as an independent risk factor for SIDS [13]. The majority of studies performed to date are not based on a sample of infants' representative of the U.S. population.

A modifiable intervention, sleep position, has been studied more closely. As a result of the Back to Sleep Campaign that was implemented in 1994, SIDS mortality rates in the U.S. have declined for all ethnic groups [16]. However, even after the implementation of the Back to Sleep Campaign, non-Hispanic Black infants were 2.14 times more likely to die from SIDS than Non-Hispanic White infants [17]. This finding is particularly problematic considering White women are much more likely to smoke during pregnancy than Black women $[14,18]$. This suggests that there may be an interaction between race and smoking status although this has not been reported to date.

This study utilized the 1988 National Maternal and Infant Health Survey (NMIHS) to examine the effect of maternal smoking status during pregnancy and secondhand smoke exposure on the prevalence of death due to sudden infant death syndrome (SIDS) using a nationally representative sample of infant deaths from the U.S. population. Previous studies utilizing the NMIHS to examine the relationship between maternal smoking and SIDS were incomplete, failing to account for breast feeding or secondhand smoke exposure $[19,20]$. The analysis presented in this manuscript accounts for both maternal smoking, as well as secondhand smoke exposure during pregnancy. Additionally, the analysis presented in this paper considers whether or not the infant was breast fed, a variable previously identified as an important protective factor against postneonatal death [21].

\section{Methods}

The 1988 National Maternal and Infant Health Survey (NMIHS) were conducted by the National Center for Health Statistics (NCHS) to assist researchers in studying factors related to poor pregnancy outcomes. The survey is a nationally representative sample of 9953 (74.2\% response rate) women who had live births, 3309 $(69.3 \%)$ that had late fetal deaths and 5332 (65.3\%) who had infant deaths in 1988. The mother's questionnaire included information on prenatal care and health habits, including tobacco smoke exposure, previous and subsequent pregnancies, characteristics of the parents and the baby's health through 6 months of age. Only the infant death group from the total study population was analyzed for this report. This study was approved by the University of Miami Institutional Review Board.

Data were abstracted from the birth certificate for the following information: birthweight, gender, gestational age, maternal age, infant race and parity. Data were abstracted from the maternal questionnaire for maternal education level, history of cigarette smoking during pregnancy, and history of alcohol use during pregnancy.

The NMIHS and Longitudinal Follow-Up drew stratified systematic samples from live births and infant deaths that were registered in 48 states, the District of Columbia, and New York City in 1988; and from fetal deaths that were registered in 46 states, the District of Columbia, and New York City in 1988. To increase the reliability of the data, Black infants were oversampled in the live-birth, fetal-death, and infant-death components of the NMIHS because Black infants have rates of low birthweight and infant mortality about twice that of White infants [22]. Very low-birthweight $(<1.500 \mathrm{~g})$ and moderately low-birthweight (1500 - $2499 \mathrm{~g})$ infants were oversampled in the live-birth component to obtain a sufficient number of high-risk births for special studies.

The live-birth and fetal-death components were restricted to women 15 years of age or over, and the infant-death component included women under 15 years of age. Mothers included in this study were women who had infant deaths and responded to the questionnaire from the NMIHS $(N=5332)$. The two study groups in the analysis consisted of (1) SIDS deaths, as defined by an ICD-9-CM code recorded as 798.0; and (2) other deaths consisting of all other infant deaths [23]. This data was obtained from linkage of the birth certificates and death certificates.

The following study independent variables were ex- 
pressed both continuously and categorically: smoking exposure, level of education, infant and maternal age, infant and maternal birthweight, maternal BMI, gender, secondhand smoke exposure, breast feeding, prenatal vitamins, WIC, multiple gestation, sleep apnea monitor prescription, sleep apnea incidents, and maternal alcohol use.

Continuous measures are reported as means with $95 \%$ confidence intervals and comparisons between the two study groups (SIDS deaths vs. other deaths) used the t-test for independent samples. Categorical measures are reported as percents with $95 \%$ confidence intervals and were compared using a Chi-square test. Multivariate logistic regression was performed to identify variables significantly associated with the odds of mortality from SIDS. Interactions between maternal smoking status and all other covariates were tested. All analyses utilized weighted estimates and were performed using SUDAAN 9.0.0 (Research Triangle Institute, Cary, NC) to adjust for design effects. A $p$-value $<0.01$ was considered statistically significant, given the very large sample size.

\section{Results}

Mothers of White infants were significantly more likely to smoke during pregnancy $(39.1 \%)$ than mothers of Black infants (34.0\%) or mothers of Other Race infants $(23.2 \%)(p<0.001)$. Mothers who smoked during pregnancy were significantly less likely to take prenatal vitamins, breast-feed the infant, and have more than a high school education. Mothers who smoked during pregnancy were also significantly more likely to give birth to multiples, use the government sponsored nutrition program, Women, Infants and Children (WIC) program, and drink alcohol during pregnancy. (Table 1)

\subsection{Univariate Analysis}

A comparison of study categorical and continuous variables, stratified by maternal race, between the SIDS deaths and other deaths are presented in Tables 2 and $\mathbf{3 .}$ All covariates included in the weighted univariate analyses, with the exception of breast feeding and use of prenatal vitamins, were significantly different between the two infant death groups $(p<0.001)$. A significantly greater proportion of mothers smoked during the 12 months preceding delivery in the SIDS mortality group $(53.3 \%)$ compared to the other mortality group $(34.2 \%)$. This finding held for both Black and White races, although a higher proportion of White smokers were represented in the SIDS mortality group. In addition to the significant variables reported in the unweighted analysis, maternal prepregnancy BMI was significantly lower in the SIDS mortality group (22.93) compared to the other
Table 1. Weighted baseline characteristics of mothers who smoked and did not smoke during pregnancy $(N=38,917)$.

\begin{tabular}{lccc}
\hline Characteristic & Non-smokers (\%) & Smokers (\%) & p-value \\
\hline Used Vitamins & 76.9 & 73.4 & $<0.001$ \\
Ever Breast fed & 43.5 & 30.0 & $<0.001$ \\
Born Preterm(<37 weeks) & 57.5 & 55.0 & $<0.001$ \\
Multiple Gestation & & & \\
Pregnancy & 10.4 & 11.4 & 0.002 \\
Used WIC & 27.7 & 36.3 & $<0.001$ \\
LBW (<2.500 g) & 58.9 & 58.7 & 0.756 \\
Used Alcohol & 34.3 & 58.1 & $<0.001$ \\
Maternal Education & & & \\
$\quad<$ High school & 21.8 & 36.1 & $<0.001$ \\
$\quad$ High school Graduate & 35.8 & 42.4 & \\
$\quad$ Some college & 42.3 & 21.4 & \\
$\quad$ & & & \\
Race $\quad$ White & 60.9 & 39.1 & $<0.001$ \\
$\quad$ Black & 66.0 & 34.0 & \\
$\quad$ Other race & 76.8 & 23.2 & \\
\hline
\end{tabular}

mortality group (23.27). The lower maternal prepregnancy BMI among the SIDS mortality group was not observed for Black infants. Maternal birth weight was significantly greater for the SIDS mortality group (3184 g) compared to the other mortality group (3122 g). This relationship was observed among White infants, but there was no significant difference in maternal birthweight between SIDS mortality groups for Black or Other Race infants.

\subsection{Multivariate Logistic Regression Analysis, Weighted and Adjusted for Design Effects}

After adjustment of standard errors using SUDAAN, the overall model was significant $(p<0.001)$. Smoking during pregnancy, use of a sleep apnea monitor, an infant that stopped breathing, infant age at death, maternal age, and infant birthweight were significant predictors of SIDS mortality. (Table 4) Women who smoked during pregnancy were 1.83 times more likely to give birth to an infant that died from SIDS versus some other cause of death, OR $(95 \% \mathrm{CI})=1.83(1.33,2.51)$. Secondhand smoke exposure through the presence of household smokers was not significantly associated with infant death from SIDS in the final model. Use of a sleep apnea monitor and an infant that was previously noted to have stopped breathing were significantly protective factors against SIDS death in the model. Infants older at the time of death and infants born to older mothers were slightly less likely to die from SIDS. The odds ratio and 95\% CI for a 1 gram increase in infant birthweight were nearly indistinguishable from 1.00 , but the birthweight 

Infant Health Survey: A Case-Case Study

Table 2. Baseline categorical characteristics (weighted) of 1988 NMIHS cohort for infant mortality groups $(N=$ 38,917).

\begin{tabular}{|c|c|c|c|}
\hline Characteristic & $\begin{array}{c}\text { SIDS Death } \\
(\%)\end{array}$ & $\begin{array}{c}\text { Other Death } \\
(\%)\end{array}$ & $p$-value \\
\hline$N$ & 5215 & 33,702 & \\
\hline \multicolumn{4}{|l|}{ Gender } \\
\hline Female & 40.8 & 44.1 & $<0.001$ \\
\hline Male & 59.2 & 55.9 & \\
\hline \multicolumn{4}{|l|}{ Mother Smoked 12 Months } \\
\hline \multicolumn{4}{|l|}{ Preceding Delivery } \\
\hline Black & 47.1 & 32.0 & $<0.001$ \\
\hline White & 59.3 & 35.9 & $<0.001$ \\
\hline Other Race & 32.4 & 20.8 & $<0.001$ \\
\hline \multicolumn{4}{|l|}{ Smokers in Home } \\
\hline \multicolumn{4}{|l|}{ During Pregnancy } \\
\hline Black & 47.1 & 45.3 & 0.230 \\
\hline White & 56.7 & 38.3 & $<0.001$ \\
\hline Other Race & 39.3 & 33.7 & 0.090 \\
\hline \multicolumn{4}{|l|}{ Mother Drank Alcohol } \\
\hline \multicolumn{4}{|l|}{12 Months Preceding } \\
\hline \multicolumn{4}{|l|}{ Delivery } \\
\hline Black & 35.8 & 31.1 & 0.001 \\
\hline White & 54.5 & 48.7 & $<0.001$ \\
\hline Other & 32.4 & 26.0 & 0.038 \\
\hline \multicolumn{4}{|l|}{ Mother Ever Breastfed } \\
\hline Black & 15.5 & 16.8 & 0.367 \\
\hline White & 43.0 & 43.8 & 0.481 \\
\hline Other Race & 61.9 & 46.4 & $<0.001$ \\
\hline \multicolumn{4}{|l|}{ Mother's Education } \\
\hline \multicolumn{4}{|l|}{ Level } \\
\hline \multicolumn{4}{|l|}{ Total } \\
\hline High School Graduate & 38.3 & 38.3 & $<0.001$ \\
\hline Some College & 26.7 & 35.9 & \\
\hline \multicolumn{4}{|l|}{ Black } \\
\hline High School Graduate & 39.2 & 40.1 & $<0.001$ \\
\hline Some College & 19.6 & 29.5 & \\
\hline \multicolumn{4}{|l|}{ White } \\
\hline High School Graduate & 39.9 & 38.4 & $<0.001$ \\
\hline Some College & 27.3 & 38.8 & \\
\hline \multicolumn{4}{|l|}{ Other } \\
\hline High School Graduate & 26.0 & 27.3 & $<0.001$ \\
\hline Some College & 29.8 & 46.2 & \\
\hline \multicolumn{4}{|l|}{ Prenatal Vitamin Use } \\
\hline Black & 63.6 & 65.6 & 0.140 \\
\hline White & 78.0 & 80.9 & $<0.001$ \\
\hline Other Race & 82.5 & 75.4 & 0.017 \\
\hline \multicolumn{4}{|l|}{ WIC Use During } \\
\hline \multicolumn{4}{|l|}{ Pregnancy } \\
\hline Black & 60.8 & 43.6 & $<0.001$ \\
\hline White & 39.4 & 21.7 & $<0.001$ \\
\hline Other & 52.8 & 25.8 & $<0.001$ \\
\hline \multicolumn{4}{|l|}{ Multiple Gestation Birth } \\
\hline Black & 6.4 & 11.4 & $<0.001$ \\
\hline White & 5.5 & 12.5 & $<0.001$ \\
\hline Other Race & 2.3 & 11.7 & $<0.001$ \\
\hline Premature Birth < 37 weeks & & & \\
\hline
\end{tabular}

\begin{tabular}{cccc}
\hline Total & 21.6 & 62.6 & $<0.001$ \\
Black & 32.6 & 73.4 & $<0.001$ \\
White & 17.4 & 58.6 & $<0.001$ \\
Other & 17.2 & 52.3 & $<0.001$ \\
& & & \\
Apnea Monitor Prescribed & & & \\
Total & 2.4 & 2.5 & $<0.001$ \\
Black & 3.3 & 1.6 & $<0.001$ \\
White & 1.9 & 2.8 & $<0.001$ \\
Other & 0.0 & 1.2 & $<0.001^{*}$ \\
& & & \\
Infant Ever Stopped & & & \\
Breathing & & & \\
Total & 17.2 & 5.2 & $<0.001$ \\
Black & 16.3 & 4.4 & $<0.001$ \\
White & 17.8 & 5.4 & $<0.001$ \\
Other & 4.2 & 5.2 & $<0.001^{*}$ \\
\hline
\end{tabular}

*indicates insufficient sample size (at least 1 cell had a count of 0 ).

Table 3. Baseline continuous measures (weighted) of 1988 nmihs cohort for infant mortality groups $(N=38,917)$.

\begin{tabular}{|c|c|c|c|}
\hline Characteristic & $\begin{array}{c}\text { SIDS Death (Mean; } \\
95 \% \text { CI) }\end{array}$ & $\begin{array}{c}\text { Other Death } \\
\text { (Mean; 95\% CI) }\end{array}$ & $\overline{p \text {-value }}$ \\
\hline$N$ & 5215 & 33,702 & \\
\hline \multicolumn{4}{|l|}{$\begin{array}{l}\text { Number of Ciga- } \\
\text { rettes/Day After } \\
\text { Knowledge of } \\
\text { Pregnancy }\end{array}$} \\
\hline $\begin{array}{l}\text { Black } \\
\text { White } \\
\text { Other }\end{array}$ & $\begin{array}{c}7.9(7.3,8.6) \\
12.3(11.9,12.7) \\
13.9(10.8,17.0)\end{array}$ & $\begin{array}{l}8.1(7.8,8.4) \\
9.1(8.9,9.3) \\
6.8(5.9,7.7)\end{array}$ & $\begin{array}{c}0.680 \\
<0.001 \\
<0.001\end{array}$ \\
\hline \multicolumn{4}{|l|}{$\begin{array}{l}\text { Maternal Level of } \\
\text { Education (Years) }\end{array}$} \\
\hline $\begin{array}{l}\text { Black } \\
\text { White } \\
\text { Other Race }\end{array}$ & $\begin{array}{l}11.6(11.5,11.7) \\
11.9(11.8,12.0) \\
10.9(10.4,11.4)\end{array}$ & $\begin{array}{l}12.1(12.0,12.2) \\
12.5(12.4,12.5) \\
12.1(11.8,12.3)\end{array}$ & $\begin{array}{l}<0.001 \\
<0.001 \\
<0.001\end{array}$ \\
\hline
\end{tabular}

Maternal Age

(Years)

Black $22.8(22.5,23.1) \quad 24.1(24.0,24.2)<0.001$

White $\quad 24.5(24.3,24.7) \quad 26.2(26.1,26.3)<0.001$

$\begin{array}{llll}\text { Other } & 23.8(23.1,24.5) & 29.1(28.8,29.5) & <0.001\end{array}$

Maternal BMI

Black $23.8(23.5,24.1) \quad 24.0(23.9,24.2) \quad 0.207$

White $\quad 22.6(22.4,22.7) \quad 23.0(22.9,23.1)<0.001$

Other $\quad 23.2(22.8,23.7) \quad 21.7(21.5,22.0)<0.001$

Maternal Birth

weight (Kg)

$\begin{array}{llll}\text { Black } & 3.00(2.95,3.05) & 3.00(2.98,3.02) & 0.993\end{array}$

White $\quad 3.25(3.23,3.27) \quad 3.17(3.16,3.18)<0.001$

$\begin{array}{llll}\text { Other } & 3.16(3.06,3.25) & 3.16(3.12,3.21) & 0.876\end{array}$

Child's Birth

weight (Kg)

$\begin{array}{llll}\text { Black } & 2.86(2.82,2.90) & 1.47(1.44,1.49) & <0.001\end{array}$

White $\quad 3.19(3.16,3.21) \quad 1.90(1.88,1.92)<0.001$

Other $\quad 3.17(3.10,3.24) \quad 2.03(1.95,2.10)<0.001$

Gestational Age $\quad 38.4(38.3,38.5) \quad 31.6(31.5,31.7)<0.001$

(Weeks)

Infant Age at

Death (Days) 
Table 4. Results of multiple logistic modeling* to assess the association between maternal smoking and infant mortality from sids (weighted), $(N=8,264)$.

\begin{tabular}{|c|c|c|}
\hline Characteristic & OR (95\% CI) & $p$-value \\
\hline \multicolumn{3}{|l|}{ Smoked During Pregnancy } \\
\hline No & 1.00 & \\
\hline Yes & $1.83(1.33,2.51)$ & $<0.001$ \\
\hline \multicolumn{3}{|l|}{ Alcohol During Pregnancy } \\
\hline No & 1.00 & \\
\hline Yes & $1.10(0.81,1.49)$ & 0.527 \\
\hline \multicolumn{3}{|l|}{ Household Smokers } \\
\hline Yes & 1.00 & \\
\hline No & $0.90(0.67,1.20)$ & 0.476 \\
\hline Maternal Age & $0.95(0.92,0.98)$ & $<0.001$ \\
\hline \multicolumn{3}{|l|}{ Maternal Level of Education } \\
\hline Some college & 1.00 & \\
\hline High school Graduate & $1.07(0.75,1.54)$ & 0.703 \\
\hline$<$ High school & $0.93(0.62,1.38)$ & 0.707 \\
\hline \multicolumn{3}{|l|}{ Multiple Gestation Pregnancy } \\
\hline No & 1.00 & \\
\hline Yes & $1.69(0.83,3.48)$ & 0.151 \\
\hline \multicolumn{3}{|l|}{ Child Gender } \\
\hline Female & 1.00 & \\
\hline Male & $1.13(0.85,1.51)$ & 0.400 \\
\hline \multicolumn{3}{|l|}{ Child Race } \\
\hline Black & 1.00 & \\
\hline White & $0.93(0.69,1.25)$ & 0.623 \\
\hline Other & $1.96(0.89,4.30)$ & 0.095 \\
\hline Gestational Age & $0.96(0.92,1.01)$ & 0.120 \\
\hline Infant Birthweight & $1.04(1.01,1.06)^{\dagger}$ & $<0.001$ \\
\hline \multicolumn{3}{|l|}{ Infant Breastfed } \\
\hline No & 1.00 & \\
\hline Yes & $1.02(0.74,1.42)$ & 0.885 \\
\hline \multicolumn{3}{|l|}{ Used Sleep Apnea Monitor } \\
\hline No & 1.00 & \\
\hline Yes & $0.21(0.10,0.44)$ & $<0.001$ \\
\hline \multicolumn{3}{|l|}{ Infant Stopped Breathing } \\
\hline No & 1.00 & \\
\hline Yes & $0.68(0.47,0.97)$ & 0.034 \\
\hline Infant Age at Death & $0.99(0.99,1.00)$ & $<0.001$ \\
\hline
\end{tabular}

effect was significant in the model $(p<0.001)$. For a 100 gram increase in infant birthweight, there was a $4 \%$ increased risk of death from SIDS as opposed to another cause. Other Race infants and Black infants were more likely to suffer SIDS mortality than White infants, but the result was not significant in the final model. An infant born as a twin or higher order gestation pregnancy was 1.69 times more likely to suffer SIDS mortality, but again, this result was not significant $(p<0.151)$. The analysis checked for interaction between smoking status and all other variables included in the final model and found no interaction present.

\section{Discussion}

The NMIHS provides a unique opportunity to gather information on a representative sample of live births and infant deaths occurring in the United States. The NMIHS continues to be the only nationally representative survey that provides information on such a wide range of health behaviors and pregnancy outcomes in conjunction with birth and demographic information. For these reasons, it remains an extremely valuable research tool despite the fact that the data reflect population characteristics that are now over 15 years old.

In this case-case study, the major finding is that smoking during pregnancy increased the risk of infant death from SIDS versus some other cause by $83 \%$. Both in this study cohort and many other populations, women who smoke in pregnancy tend to have different sociodemographic characteristics than non-smokers [18, 24]. Because these factors may also be associated with risk for SIDS, concern exists that associations may reflect sociodemographic confounding rather than a causal relationship. However, in this study, adjustment for factors such as maternal education and race only minimally influenced effect sizes. We found no evidence of an interaction between race and maternal smoking status.

Several researchers have corroborated the maternal smoking and SIDS relationship. Taylor and Sanderson used the NMIHS to conduct a study of risk factors for SIDS and found maternal smoking during pregnancy was significantly more common among infants that died from SIDS than in infants dying from other causes, OR $(95 \%$ CI $)=1.97(1.59,2.45)[20]$. They did not control for breast feeding or other smokers in the home during pregnancy. Schoendorf and Kiely, who also analyzed the NMIHS data, but stratified the analysis by race, and only included normal birthweight babies, demonstrated that maternal smoking is a more significant risk factor for SIDS than for other postneonatal deaths [19].

It was expected that Black infants would be at an increased risk for SIDS considering the fact that previous studies have identified Black race as a pertinent risk factor. The final model of the present study suggested Black infants are at a slightly increased risk for death from SIDS compared to White infants; however, this result was not significant. Infants of "Other Race" were actually 1.96 times more likely to suffer SIDS mortality than Black infants, although this result also failed to reach statistical significance. Only 34 valid "Other Race" infants were included in the SIDS analysis, most of which were Asian or American Indian. Hispanic eth- 
nicity was distributed among White, Black, and Other Race infants and was not readily isolated in this analysis. Although race was not a significant predictor of SIDS mortality, future studies should pay special attention to American Indians, a group in which SIDS accounted for $81.8 \%$ of infant deaths in addition to representing a group where smoke exposure during pregnancy is highly prevalent. These results further highlight the importance of counseling women against smoking during pregnancy and providing access to cessation programs.

Bed-sharing and sleep position have been implicated as risk factors for SIDS and pacifier use during sleep has been implicated as a protective factor for SIDS; however, these variables were not available for analysis in the NMIHS $[25,26]$. The NMIHS and Longitudinal Follow-Up were conducted prior to the initiation of the Back to Sleep campaign. Sleep behaviors are pertinent variables to consider as risk factors for SIDS mortality because of their possible impact on the infant's control of arousal mechanisms, but due to limitations of the dataset, only smoke exposure could be assessed [27].

In addition to smoking during pregnancy, use of a sleep apnea monitor and the infant having ever stopped breathing were significantly associated with risk of SIDS mortality. Use of a sleep apnea monitor decreased the risk of SIDS mortality by $79 \%$, and noticing the infant had stopped breathing reduced the risk of SIDS mortality by $32 \%$. The univariate analysis indicates Black infants that died from SIDS were more likely to have been prescribed a sleep apnea monitor and that infants that stopped breathing were more likely to have died from SIDS; however, the final regression model found the association reversed. There were high percentages of missing cases for both of these variables, possibly reducing the validity of conclusions drawn about these relationships. An analysis of the NMIHS using SIDS deaths and live controls also described a protective effect of home apnea monitoring [28].

It is important to note when interpreting the analysis that a distinction should be made between statistical significance and clinical significance. The large sample size produced by weighting often times results in very small $p$-values that reflect small effect estimates of questionable clinical relevance. In Table 1, for example, one might expect a significantly higher percentage of preterm infants to be born to smokers rather than to non-smokers, rather than vice-versa. Prematurity is a common characteristic among infants suffering all causes of mortality; and it is likely that the statistically significant difference seen between smokers and nonsmokers regarding prematurity is the product of the large sample size, and not a clinically important observation.
SIDS continues to be a major cause of postneonatal death. Although lower than in 1988, the prevalence of smoking during pregnancy continues to be substantial, both in the U.S. and other Western countries. With overall smoking prevalence among women increasing in many countries, maternal smoking is clearly an important international health issue. In many developing countries, the lack of adequate health facilities, and tobacco education or control programs can increase the health risks of maternal smoking on the fetus and infant. Importantly, this analysis found neither race, nor socioeconomic status, were significantly associated with SIDS risk, suggesting universal tobacco screening and education during pregnancy should be undertaken. Finally, while many health benefits of breast feeding have been identified, this study failed to find a significant protective effect of breast feeding in reducing the risk of SIDS mortality. Further study of this topic is needed before breast feeding can be recommended or discounted as a modifiable risk factor in the prevention of SIDS. The relationship between maternal smoking status and SIDS was clear. The importance of abstaining from tobacco smoke exposure during and after their pregnancy should be stressed when educating all pregnant women how to maintain a healthy pregnancy and smoking cessation guidance should be made available to all pregnant women with a positive screen.

\section{REFERENCES}

[1] R. Machaalani, K. A. Waters and K. D. Tinworth, "Effects of Postnatal Nicotine Exposure on Apoptotic Markers in the Developing Piglet Brain," Neuroscience, Vol. 132, No. 2, 2005, pp. 325-333. doi:10.1016/j.neuroscience.2004.12.039

[2] T. A. Slotkin, "Cholinergic Systems in Brain Development and Disruption by Neurotoxicants: Nicotine, Environmental Tobacco Smoke, Organophosphates," Toxicology and Applied Pharmacology, Vol. 198, No. 2, 2004, pp. 132-151. doi:10.1016/j.taap.2003.06.001

[3] L. Sartiani, E. Cerbai, G. Lonardo, et al., "Prenatal Exposure to Carbon Monoxide Affects Postnatal Cellular Electrophysiological Maturation of the Rat Heart," Circulation, Vol. 109, 2004, pp. 419-423. doi:10.1161/01.CIR.0000109497.73223.4D

[4] R. A. Neff, S. J. Simmens, C. Evans and D. Mendelowitz, "Prenatal Nicotine Exposure Alters Central Cardiorespiratory Responses to Hypoxia in Rats: Implications for Sudden Infant Death Syndrome," The Journal of Neuroscience, Vol. 24, No. 42, 2004, pp. 9261-9268. doi:10.1523/JNEUROSCI.1918-04.2004

[5] C. A. Browne, P. B. Colditz and K. R. Dunster, "Infant Autonomic Function Is Altered by Maternal Smoking during Pregnancy," Early Human Development, Vol. 59, 
No. 3, 2000, pp. 209-218. doi:10.1016/S0378-3782(00)00098-0

[6] W. P. Fifer, S. T. Fingers, M. Youngman, E. Gomez-Gribben and M. M. Myers, "Effects of Alcohol and Smoking during Pregnancy on Infant Autonomic Control," Developmental Psychobiology, Vol. 51, No. 3, 2009, pp. 234-242. doi: $10.1002 /$ dev.20366

[7] J. R. Duncan, M. Garland, M. M. Myers, et al., "Prenatal Nicotine-Exposure Alters Fetal Autonomic Activity and Medullary Neurotransmitter Receptors: Implications for SIDS," Journal of Applied Physiology, Vol. 107, No. 5, 2009, pp. 1579-1590.

doi:10.1152/japplphysiol.91629.2008

[8] O. Hafström, J. Milerad, K. L. Sandberg and H. W. Sundell, "Cardiorespiratory Effects of Nicotine Exposure during Development," Respiratory Physiology and Neurobiology, Vol. 149, No. 1-3, 2005, pp. 325-341. doi:10.1016/j.resp.2005.05.004

[9] A. Lindblad, K. Marsal and K. E. Andersson, "Effect of Nicotine on Human Fetal Blood Flow," Obstetrics and Gynecology, Vol. 72, No. 3, 1988, pp. 371-382.

[10] G. Thiriez, M. Bouhaddi, L. Mourot, et al., "Heart Rate Variability in Preterm Infants and Maternal Smoking during Pregnancy," Clinical Autonomic Research, Vol. 19, No. 3, 2009, pp. 149-156. doi:10.1007/s10286-009-0003-8

[11] R. A. Pierce and N. M. Nguyen, "Prenatal Nicotine Exposure and Abnormal Lung Function," American Journal of Respiratory Cell and Molecular Biology, Vol. 26, No. 1, 2002, pp. 10-13.

[12] R. W. Byard and H. F. Krous, "Sudden Infant Death Syndrome: Problems, Progress and Possibilities," Arnold, London, 2001.

[13] N. Spencer and S. Logan, "Sudden Unexpected Death in Infancy and Socioeconomic Status: A Systemic Review," Journal of Epidemiology and Community Health, Vol. 58, No. 5, 2004, pp. 366-373. doi:10.1136/jech.2003.011551

[14] V. T. Tong, J. R. Jones, P. M. Dietz, D. D'Angelo and J. M. Bombard, "Trends in Smoking before, during and after Pregnancy. Pregnancy Risk Assessment Monitoring System (PRAMS), United States, 31 Sites, 2000-2005," Morbidity and Mortality Weekly Report, Vol. 58, No. SS04, 2009, pp. 1-29.

[15] S. Kafouri, G. Leonard, M. Perron, L. Richer, J. R. Séguin, S. Veillette, Z. Pausova and T. Paus, "Maternal Cigarette Smoking during Pregnancy and Cognitive Performance in Adolescence," International Journal of Epidemiology, Vol. 38, No. 1, 2009, pp. 158-172. doi:10.1093/ije/dyn250

[16] M. Willinger, C.-W. Ko, H. J. Hoffman, R. C. Kessler and M. J. Corwin, "Factors Associated with Caregivers'
Choice of Infant Sleep Position, 1994-1998: The National Infant Sleep Position Study," The Journal of American Medical Association, Vol. 283, No. 16, 2000, pp. 2135 2142. doi:10.1001/jama.283.16.2135

[17] P. Muhuri, M. F. MacDorman and T. M. Ezzati-Rice, "Racial Differences in Leading Causes of Infant Death in the United States," Paediatric and Perinatal Epidemiology, Vol. 18, No. 1, 2004, pp. 51-60. doi:10.1111/j.1365-3016.2004.00535.x

[18] T. J. Mathews, "Smoking during Pregnancy in the 1990s," National Vital Statistics Reports, Vol. 49, No. 7, 2001, pp. 1-14.

[19] K. C. Schoendorf and J. L. Kiely, "Relationship of Sudden Infant Death Syndrome to Maternal Smoking during and after Pregnancy," Pediatrics, Vol. 90, No. 6, 1992, pp. 905-908.

[20] J. A. Taylor and M. Sanderson, "A Reexamination of the Risk Factors for the Sudden Infant Death Syndrome," The Journal of Pediatrics, Vol. 126, No. 6, 1995, pp. 887-891. doi:10.1016/S0022-3476(95)70202-4

[21] A. Chen and W. J. Rogan, "Breastfeeding and the Risk of Postneonatal Death in the United States," Pediatrics, Vol. 113, No. 5, 2004, pp. 435-439. doi:10.1542/peds.113.5.e435

[22] Public Health Service, "National Center for Health Statistics. Health, United States, 1991," Hyattsville, USA, 1992.

[23] Public Health Service and Health Care Financing Administration, "International Classification of Diseases, Ninth Revision, Clinical Modification," Washington, USA, 1980.

[24] Department of Health and Human Services, "National Center for Health Statistics. Health, United States, 1998 with Socioeconomic and Health Chartbook," Hyattsville, USA, 1998.

[25] M. Mitka, "Policy Targets Lowering SIDS Incidence," The Journal of American Medical Association, Vol. 294, No. 19, 2005, p. 2420. doi:10.1001/jama.294.19.2420

[26] D.-K. Li, M. Willinger, D. B. Petitti, R. Odouli, L. Liu and H. J. Hoffman, "Use of a Dummy (Pacifier) during Sleep and Risk of Sudden Infant Death Syndrome (SIDS): Population Based Case-Control Study," British Medical Journal, Vol. 332, No. 7532, 2005, p. 18. doi:10. 1136/bmj.38671.640475.55

[27] H. L. Richardson, A. M. Walker and R. S. Horne, "Maternal Smoking Impairs Arousal Patterns in Sleeping Infants," Sleep, Vol. 32, No. 4, 2009, pp. 515-521.

[28] M. H. Malloy and H. J. Hoffman, "Home Apnea Monitoring and Sudden Infant Death Syndrome," Preventive Medicine, Vol. 25, No. 6, 1996, pp. 645-649. doi:10.1006/pmed.1996.9998 